\title{
CONTEXTO POLÍTICO DE LOS DERECHOS HUMANOS: SOCIEDAD, GOBERNABILIDAD Y VIOLENGIA
}

(Recibido: Mayo 3 de 2011 Aprobado: Junio 28 de 2011)

Manuel José Acebedo Afanador**

"Colombia es un Estado social de derecho..."

"Son fines esenciales del Estado: servir a la comunidad, promover la prosperidad general y garantizar la efectividad de los principios, derechos y deberes consagrados en la Constitución..."

Constitución Política de Colombia Arts. 1 y2

\section{Resumen}

Desde la hipótesis de la ruptura histórica entre la sociedad civil y el Estado, la ausencia de lazos dialógicos, se trata de hacer una reflexión sobre la relación entre los fenómenos de corrupción, pobreza y violencia en el marco del concepto de gobernabilidad. Las violencias que atraviesan permanentemente la historia de Colombia tienen su origen en las endémicas: corrupción y pobreza, que han acompañado siempre la historia nacional. Esto es, la estructuración de Estado-nación en Colombia con fundamento en la dignidad, en los derechos humanos, en la paz entendida como la realización de los derechos humanos, en un maduro sentido de la política y un compromiso ciudadano ético, crítico y participativo, con el soporte de un Estado eficaz, eficiente y garantista, no pasa de ser una proclama vacía; pues la realidad es de permanente violación de derechos, poca participación, relación pragmática y utilitaria entre el Estado y sus ciudadanos (nótese en las elecciones), con lo que se frustra permanentemente la construcción de Estado-nación e impide la realización de la paz como una paz integral, que se fundamente en la ausencia de violencia contra todos los derechos humanos.

\section{Palabras clave}

Estado-Nación, Derechos Humanos, Pobreza, Corrupción, Violencia, Dignidad

\section{POLITICAL CONTEXT OF HUMAN RIGHTS: SOCIETY, GOVERNABI- LITY AND VIOLENGE}

\section{Alostract}

From the hypothesis of the historical split between civil society and state, the absence of dialogical relationships, it is a reflection on the relationship between the phenomena of corruption, poverty and violence in the framework of the concept of governance. The violence that constantly go through the history of Colombia have their origin in the endemic, corruption and poverty that have always accompanied the history of Colombia. That is, the structure of nation-state in Colombia on the basis of the dignity, human rights, peace, understood as the realization of human rights in a mature sense of political and ethical civic engagement, critical and participatory with state support effective, efficient and guarantees, no more than a proclamation empty because reality is permanent violation of rights, low participation, utilitarian and pragmatic relationship between the state and its citizens (note in the elections), which permanently frustrated nation-state building and prevents the realization of peace and a comprehensive peace that is based on the absence of violence against all human rights.

\section{Key words:}

Nation-State, Human Rights, Poverty, Corruption, Violence, Dignity

\footnotetext{
* Artículo de reflexión producto de investigación personal 2010

* Sociólogo. Licenciado en Filosofía con Especialidad en Historia. Diplomado en Investigación. Especialista en Instituciones Jurídico-Políticas y Derecho Público. Especialista en Educación en Derechos Humanos. Magíster en Evaluación en Educación. Actualmente cursa el Doctorado en Educación y Currículo con la Universidad de Granada (Granada, España). macebedo@unab.edu.co
} 


\section{INTRODUCCIÓN}

En Colombia se ha dado una ruptura histórica, una dicotomía, entre la Sociedad Civil y el Estado, contradictoriamente, en la misma medida que se ha tratado de estructurar el Estado-Nación.

Con la sugestión de la hipótesis, parece ser que en la construcción del Estado Nación Colombiano, primero se intentó estructurar una suerte de Estado formal, luego se le dio el carácter -también formal- de nación, más tardíamente de país (como estructura de territorio) y después se le agregó al pueblo -a la gente-, pero como carne de cañón, como rebaño electoral o como objeto de explotación económica, todo al revés; sólo tardíamente, desde mediados del siglo $X X, y$ muy despacio, empiezan a reconocerse derechos humanos a la gente y esto de modo accidentado, en medio de luchas populares y con permanentes zarpazos en su contra.

\section{GOBERNABILIDAD Y SOCIEDAD}

En nuestro medio, autárquico en el ejercicio del poder político, el concepto de gobernabilidad, que "no es sólo el ejercicio del poder, sino además todas las condiciones necesarias para desempeñar esta función con eficacia, legitimidad y respaldo social" (BID, 1996), se ha definido generalmente desde la visión del gobernante.

En el caso que nos ocupa, con una óptica sociológica, el concepto se enfoca desde la vida social, en las creencias políticas de la sociedad civil, en su relación con la realización de los derechos humanos y en el sentido de la juridización que es el proceso social paulatino a través del cual el derecho incrementa su carácter de normativa escrita. Este incremento se da tanto por extensión, al regular jurídicamente mayor cantidad de ámbitos sociales que estaban regulados informalmente, como por densidad, o sea, "des- menuzación de una materia jurídica general en varias materias particulares", ( $\mathrm{Habermas}$, 1999. Pp. 447 y ss) especialmente en el ámbito de los Derechos Humanos, ${ }^{1}$ también con respecto a las organizaciones de todo tipo que se autoproclaman como "represen-

tantes" de los intereses de los ciudadanos de manera difusa, sin mucha claridad sobre su legitimidad de la representación y la cobertura de representados.

Súmese, en la realidad cotidiana, todas las tragedias que atraviesa la sociedad colombiana y que fracturan permanentemente el sentido de la gobernabilidad y de la gobernanza. Sería suficiente con leer las estadísticas de muertes violentas y compararlas con los países que ocupan los otros "lugares de honor" en esta macabra lista, para notar la abismal diferencia con los siguientes lugares; o retomar la criminal "combinación de las formas de lucha" (Vargas Velásquez, 1992) (el Estado es garante de la legalidad, pero algunos gobernantes permiten e, inclusive, fomentan lo ilegal para mantener el poder, los paramilitares son el mejor ejemplo), o la ausencia real de participación ciudadana (bien por negligencia, por desconocimiento o por la poca apertura del Estado a los ciudadanos), o lo que reflejan las estadísticas de organizaciones como el CINEP o CODHES, incluso organizaciones internacionales como la $\mathrm{FAO},{ }^{2}$ que acaba de producir un dramático informe sobre la corrupción y la violencia en el reparto de tierras, así como las acciones demencialmente criminales de los grupos armados de izquierda y derecha. 
Sobre estas cosas en aras, al menos, de pensar el problema como ciudadano común y corriente, se hace este intento de reflexión:

Aunque los medios masivos de información social hagan aparecer las crisis colombianas siempre alrededor de algún tipo de crisis institucional, en el circo mediocre del enfrentamiento de poderes y de sectores de clase, la más profunda ruptura en nuestro país se presenta entre la sociedad civil (como estructura social) y el Estado (como estructura jurídicopolítica), aunada al crecimiento diario del abismo entre economía y sociedad. ${ }^{3}$ Ahora bien, estas crisis son necesarias para los grupos que detentan el poder y necesitan continuar el status quo; así, de vez en cuando sacrifican a miembros de su propio medio o arman, al menos, escándalos publicitarios, como hicieron, por ejemplo, con Fernando Botero Zea o de los políticos quemados en el proceso 8.000, o del caso de Foncolpuertos, o de las acciones del ex ministro F. Londoño, o de la parapolítica, entre muchos otros. Desde esta perspectiva, el Estado es un instrumento de dominación de cierto grupo económico-político sobre el grueso de la sociedad; entendido este poder, con N. Bobbio, desde "...la denominada tipología de los tres poderes, económico, ideológico y político, o sea de la riqueza, del saber y de la fuerza" (Bobbio, 1987. Pp. 91-92)

Desde el gobierno de Belisario Betancur C. y con más fuerza después de 1991, nuevos elementos -sin romper el bipartidismo ni las hegemonías de todo tipo (religiosas, económicas y demás)han empezado a hacer presencia en el armazón estatal, tal como sucede con los indígenas, nuevos grupos de izquierda, líderes cívicos, alcaldes provenientes de sectores no tradicionales, entre otros, que, sin mucha fuerza política o económica, han venido tomando algunos espacios para tratar de construir propuestas alter- nativas a las tradicionales del bipartidismo y aún a las viejas corrientes de izquierda.

Estos nuevos elementos no han logrado cambios significativos dentro del aparato de Estado, pues han tenido que convivir con las fuerzas tradicionales, ${ }^{4} \mathrm{y}$ estos partidos y grupos que han detentado siempre el poder no han permitido, ni permitirán mientras puedan, cambios significativos en el país político o económico, porque siempre implicaría para ellos algún tipo de dolorosa -o generosarenuncia; además, algunos de estos nuevos elementos han terminado por caer en el juego politiquero tradicional, como el patético caso de la ADM19, Convergencia Ciudadana, el lento desmoronamiento del Polo Democrático, u otros que han surgido desde la derecha para mantener y ahondar el estado actual de cosas pero disfrazando el bipartidismo (el partido de la U y Cambio Radical para nombrar dos casos ejemplarizantes).

En tercer lugar, también es el Estado en Colombia un reflejo de las contradicciones existentes de la sociedad civil, en teoría como lo propone el griego Poulantzas, (Poulantzas, 1977) pues existen en el Estado las mismas contradicciones que en la sociedad civil, agravadas por las tensiones entre los poderes, recurrentes en Colombia, en los que

(...) la división de poderes no funciona: el Ejecutivo avasalla al Judicial, el |Legislativo medra del Ejecutivo $y$, para rematar, los 'trances' entre el Congreso y la Justicia son cada vez más notorios. La Procuraduría pone en cuestión a la Fiscalía; la Corte Suprema a la Procuraduría; el Fiscal y el Procurador se jalan las mechas; la Corte y la Cámara están al borde de un ataque de nervios. Mejor dicho, como dice Celia Cruz: Bernabé le pegó a Muchilanga(...); (Molano, 1996, p. 4A)

de tal manera que, los que han manejado el Estado como un instrumento de 
poder, a su vez lo manipulan internamente con enfrentamientos y contradicciones intra -clase y entre sectores políticos, que hasta hace un tiempo, luchaban hegemónicamente por mantener el poder frente nacionalista (Ramirez V., 1996)

Además, desde la sociedad ha habido una trasferencia de responsabilidad y expectativas al gobernante, como un fenómeno psicosocial en busca del "buen padre" del "tótem milagroso":

Después del fallo absolutorio al presidente Samper, en aquella misma época con las conversaciones entre sectores aparentemente irreconciliables en torno a la propuesta presidencial del "borrón y cuenta nueva" y de "reconciliación nacional", o las rápidas y poco claras negociaciones de desarme con algunos paramilitares, ante lo que todos los sectores en pugna llegaron a acuerdos coyunturales, lo mismo con Pastrana Arango, con la unidad que alcanzó a lograr con las expectativas de paz con las FARC y la profunda decepción social que causó al final el rompimiento y la conducta de las partes, especialmente de la guerrilla, se llegó a una espontánea y emocional unidad ciudadana a favor de las salidas rápidas y duras al conflicto y permitió una mala negociación con los paramilitares para que resucitaran con las BACRIM, más violentas y dispersas, pero sí terminó por reflejar otra cosa: el miedo a la libertad, (Fromm, 2008) un deseo de encontrar en el gobernante al padre bueno y a la vez riguroso e incluso castigador (el patriarca) que orienta la vida y excluya de toda responsabilidad histórica al ciudadano mientras le permite la sensación de que participa mediante consejos comunales y consultas $u$ opiniones radiales. ${ }^{5}$

A esta cuestión se suma el rápido aumento de la indisciplina social, producto de fenómenos como la acelerada urbanización, que ha acabado con cierto orden de vida campesina, signada fuertemente por el poder hierocrático ${ }^{6}$ de la Iglesia católica como elemento garante del orden social, que ha conducido a una nueva forma de vida que no corresponde a lo propiamente citadino ni a lo rural y que ha hecho de la ciudad un espacio de creciente ingobernabilidad; que, a su vez, tampoco se constituye únicamente por la pobreza, pues la indisciplina social en zonas de mucha capacidad económica es notoria (cosa de pasearse por los sectores de estrato cinco y seis de cualquier ciudad y observar, por ejemplo, el irrespeto a las normas de tránsito o la invasión de espacios públicos); tampoco expresa una ruralización de la ciudad, pues las formas culturales de los inmigrantes, a pesar de ser marginales, no son las mismas de su antiguo medio campesino, conformando un híbrido cultural sin identificación propia y con tendencia al machismo, a la violencia, a nuevas formas de religiosidad (satanismo, cultos de la nueva era, sectas pseudoprotestantes y otras) -alienantes y peligrosas-, sin que tampoco renuncien muy claramente a sus creencias católicas tradicionales-, a la utilización de formas privadas de manejo de conflictos y al desencanto por lo público y por lo político, desencanto que se puede soslayar solamente en el índice de crecimiento en la abstención electoral, que ha pasado del $27,7 \%$ en el plebiscito de 1957 al $70 \%$ en la Constituyente de 1990, (Vargas Velásquez, Participación y Democracia en Colombia) y que se ha mantenido en los últimos procesos electorales a pesar de la Constitución de 1991 y sus ínfulas participativas, sin sumar aquí la socorrida pero muy cierta decepción producida por la corrupción en el manejo de las instituciones del Estado por parte de la clase política y de la burocracia en términos generales, corrupción por acción o por omisión. En las últimas elecciones, por ejemplo, el alto grado de favorabilidad por tal o cual candidato presidencial se debe más a circunstancias coyunturales que al propio carisma o calidad del respectivo candidato. ${ }^{7}$

Así se podría afirmar en primera instancia, que, por su continuidad a través de la historia de Colombia, parece que las crisis 
de gobernabilidad en el fondo no se dan en el sentido clásico del concepto, de ruptura y de origen dialéctico de nuevas formas de relaciones sociales; sino que son formas de "reciclaje histórico", unas un poco más radicales que otras, o por lo menos, más publicitadas en aras de algún tipo de interés, bien sea nacional o internacional, si se considera el enfrentamiento entre algunas esferas del poder político, entre el sector económico y el gobierno y la injerencia de los norteamericanos; sin que hasta aquí se pueda mencionar a la sociedad civil como protagonista de la cuestión, si no es únicamente como objeto de manipulaciones, de excusa para el mantenimiento de cierta ideología o de alguna tendencia o como víctima de los radicalismos que asesinan diariamente las esperanzas de miles de colombianos; además, una crisis cuando es demasiado larga (la nuestra va para dos siglos ininterrumpidos), o mata al que la sufre, o, como parece que es el caso colombiano, se habitúa a ella de tal manera que termina como parte de su ser y de su propia y peculiar forma de entender la "normalidad"; o, como dice el Escudo Colombiano: "Libertad y Orden", pero dentro de nuestra propia concepción de libertad y de orden: libertad para hacer de la arbitraria subjetividad personal o de grupo la ley exclusiva y orden para aprender a "burlar la ley sin violarla y violarla sin castigo", (Acebedo Afanador, 1995).

A este nivel, con la misma sugestión de la hipótesis, parece que la clase política no se renueva sino que de una u otra manera se "recicla" (para el caso no es sino analizar con lupa la composición del Congreso Colombiano después de las elecciones de 2003, que en su momento hicieron alharaca de renovación y cambio, o lo que resulta en las elecciones de 2011, en las que el poder a la sombra de muchos gobernadores y alcaldes queda en los patios de las cárceles de máxima seguridad), mientras la sociedad civil ahonda su distanciamiento del Estado con el aumento del escepticismo; y en el fondo, como una impresión de primera mano, en el gran grueso de la población colombiana queda la sensación de que, a pesar de la alharaca periodística, aquí termina por no pasar nada y todo sigue igual; por lo tanto, aquí no vale la pena comprometerse con nada diferente al entorno inmediato. Lo que rompe de tajo con el sentido del ciudadano como constructor de Estado y de cohesión social, reduce a los individuos a la pura pragmática su fuero privado.

\section{GOBERNABILIDAD Y VIOLENCIA}

\section{REFLEXIONES INICIALES ${ }^{8}$}

"La paz es un bien tal que no se puede desear otro mejor ni querer otro más útil"

San Agustín

La paz se concibe muy a menudo sólo en forma negativa, es decir, como la ausencia de sus opuestos. Sin embargo, se sabe que una paz auténtica y viviente, no consiste en la imposible supresión de los conflictos, sino en la radical renuncia a toda forma violenta de superar las contradicciones y resolver los problemas.

La paz es un bien supremo porque le permite al hombre ser en lo que tiene de más humano: en la solidaridad, la comunicación y en el enriquecimiento personal y social, la Constitución de 1991, por ejemplo, como un derecho humano.

El artículo 22 de la Carta Política proclama que: "la paz es un derecho y un deber de obligatorio cumplimiento", así,

La paz es el objeto de un derecho pleno e inalienable que se debe a cada hombre por justicia, como se le debe la vida, la libertad, la justicia y la honra. Es más que un valor, un ideal o un principio. 
La paz es una de las esenciales características que se atribuyen al ser humano en virtud de su propia naturaleza.

Entre otras características, del Derecho a la Paz podría decirse que es:

Fundamental: porque hace parte de los bienes jurídicos inherentes a la persona.

Preexistente: porque su positivización en el texto constitucional, es un acto declarativo y no constitutivo.

Universal: porque su titularidad corresponde a todos los seres humanos.

Inalienable: porque nadie tiene facultades para realizar actos de disposición sobre su contenido esencial.

Irreductible: porque su ejercicio únicamente puede ser regulado a través de una ley estatutaria.

Inviolable: Porque actúa contra la justicia, quien lo hace objeto de vulneración o amenaza.

La paz, además de un derecho, como se acaba de caracterizar, es también un deber. Cada miembro de la familia humana está obligado en conciencia a proceder de modo pacífico, en el marco de sus relaciones familiares, sociales, económicas y políticas.

El artículo 1 de la Declaración Universal de los Derechos Humanos es taxativo al respecto:

Todos los seres humanos nacen libres e iguales en dignidad y derechos, y, dotados como están de razón y conciencia deben comportarse fraternalmente los unos con los otros. Esta fraternidad entre los hombres exige a cada uno de ellos abstenerse de emplear la fuerza ilegítima, para hacer que prevalezca su voluntad, su interés o su punto de vista. Como derecho y como deber la paz se identifica con el desarrollo integral de la persona y con el crecimiento solidario de la persona y con el desarrollo integral de la persona y con el crecimiento solidario de la humanidad. Uno y otro están directamente relacionados con la defensa y la promoción de los derechos humanos, pues los hombres y los pueblos, sólo pueden alcanzar su pleno desenvolvimiento dentro de una convivencia fundada en el respeto efectivo de lo humana dignidad y de los atributos jurídicos esenciales que de ella emanan. El desarrollo no es posible sin la paz, pero al mismo tiempo no es concebible la paz sin la justicia. La paz no puede ser asunto de unos cuantos hombres y mujeres creyentes y ateos, miembros de este o aquel partido, gobernantes y gobernados, tenemos un compromiso con su logro y con su mantenimiento porque cada uno de nosotros está llamado a gozar de sus frutos, beneficios y ventajas. La edificación de la paz debe ser una empresa colectiva frente a la cual no haya neutralidades y ausencia.

Así, el problema de la paz nos atañe a todos.

\subsection{FORMAS DE VIOLENCIA}

\subsubsection{VIOLENCIA LÚDICA}

Este aspecto engloba la violencia que no es patológica, pues no hay en ella odio, deseo de destrucción, venganza o malignidad de forma manifiestamente consciente, pero no por ello deja de ser destructiva.

Se asume generalmente como normal dentro de cierto medio cultural y permite el desfogue de fuerzas físicas y mentales a través de actos violentos pero permitidos; es el caso del boxeo, del toreo y la lucha en algunas de sus modalidades y otros.

Aunque no se ve la intencionalidad destructora, $y$, a pesar de ser considera- 
dos deportes, si se nota el deseo de bloquear, de hacerse héroe en la medida que comete heridas a otro ser vivo. Esto lleva a alimentar y cultivar rasgos violentos que avanzan y forman a los espectadores en esta actitud. Se aplaude con entusiasmo la herida abierta en el contrincante o la muerte física. Hay otros no destructivos de muertes simbólicas, como en los deportes de esgrima o de tiro al blanco, entre otros. Es una escuela de la violencia en deportes que realmente producen heridas o muerte a un ser vivo para complacencia del auditorio. Inclusive en deportes como el fútbol la violencia del fanatismo también ha comenzado a hacer carrera.

\subsubsection{VIOLENCIA REACTIVA}

Se realiza en defensa de la vida, en reconquista de la libertad, en la protección de la dignidad, de los derechos, de la propiedad y otros. Esta violencia admite mayor justificación, pero no por ello deja de ser menos nociva e indeseable, sino que se afirma que no es de la misma naturaleza de aquella que se realiza por el simple gusto de destruir, de aterrorizar, de adquirir poder; se ve como extrema salida a conflictos originados en algún tipo de injusticia o abuso, con raíces impregnadas por el miedo, los prejuicios, la duda o la manifiesta inferioridad de condiciones. “Esta clase de violencia está al servicio de la vida, no de la muerte, pues su fin es la defensa y no la destrucción por la destrucción (...)." (Fromm, 1982, p. 21)

Ahora bien, esta explicación de la violencia puede también convertirse en justificación que disfrace otros tipos de violencia. Ocurre con enorme frecuencia en Colombia, cuando se justifican las violaciones de derechos, los grupos paramilitares o las Convivir por la existencia de la guerrilla; cuando se explica el terrorismo guerrillero por la acción violenta del Estado sobre sus ciudadanos; la violencia callejera de reacciones extremas ante agresiones leves o no culposas; las agresiones de los padres frente a los hijos que violan ciertas normas familiares; para citar algunos ejemplos.

De esta manera, la violencia reactiva produce imparables reacciones en cadena: tú hablas fuerte, yo grito; tú gritas, yo te golpeo; tú golpeas, yo te acuchillo; tú me acuchillas, yo te disparo; tú me disparas, yo masacro tu familia (...)

\subsubsection{VIOLENCIA POR FRUSTRACIÓN}

Se da en el mismo momento que se frustra un deseo o necesidad y se manifiesta con una conducta agresiva; Tiene como finalidad conseguir el propósito que no ha sido alcanzado.

Esta clase de violencia es connatural a toda forma viviente, especialmente a la especie humana, con reacciones naturales por instinto, con pocos casos de verdadero daño a otra especie o a sus propios congéneres. Sin embargo, sí es altamente destructiva cuando ocurre con personas mimadas e indefensas o parásitas, a quienes todo les debe salir bien o si no reaccionan de manera agresiva.

En esta perspectiva, el otro no existe como otro en el sentido alterizante del concepto, sino como parte opositora que me hace competencia, me limita, me supera y tiene una mayor potencialidad que afecta mi ego de manera patológica y origina respuestas destructivas y dañinas. "Con la agresión resultante de la frustración se relaciona la hostilidad producida por la envidia y por los celos" (p. 23)

Esta violencia hoy en día, en nuestro medio, se expresa en la competencia por sobrevivir, por mantenerse en el mercado, por conseguir o ascender en el trabajo, por la perversa aplicación como norma de vida cotidiana de lo que coloquialmente se denomina "los undécimos y duodécimo mandamientos": "No dar papaya" $y$ "si le dan papaya aproveche". 


\subsubsection{VIOLENCIA VENGATIVA}

Tiene mucha afinidad con la reactiva, tiene como finalidad evitar el daño que amenaza, está al servicio de la supervivencia, pero de manera patológica. Se actúa con referencia a un caso pasado y como consecuencia del presente; por tanto, no tiene como fin último la defensa sino la destrucción. Es irracional y conduce a un intenso deseo de destrucción objetivado y definido en torno a un objeto predeterminado y por razones basadas en reacciones de carácter emocional.

Este tipo de violencia ha sido bastante común en el género humano a través de todos los tiempos; con agravamientos dramáticos, como ha ocurrido en Colombia, recién pasadas las épocas de guerras civiles, con las venganzas, sobre todo familiares, que se suscitaron después de la guerra de los mil días, de la violencia política de los años cincuenta y que ocurre hoy en día diariamente.

\subsubsection{VIOLENCIA COMPENSADORA}

Tiene sus raíces en la incapacidad del ser humano para actuar ante determinada situación positiva que le permite su realización. La violencia compensa entonces tal impotencia puesto que quien no puede crear entonces destruye lo que o al que puede.

Es común a toda persona la trascendencia, que, por definición, es positiva. Pero cuando alguien es incapaz de cambio y transformación hacia mejor, entonces opta por la destrucción como camino hacia cierto tipo negativo de trascendencia, como una forma de "ser capaz", de mostrar poder y mantener el orgullo y el prestigio y por lo tanto cierta autoestima que en el fondo esconde una pobre imagen de sí mismo. "Lo que aquí importa no es el ámbito o enlace de la voluntad y la libertad, sino el hecho de que el hombre no puede tolerar la pasividad absoluta" (p. 29)

Esta violencia es tan profunda y arraigada como el mismo deseo de vivir, normalmente es el resultado de una vida sin posibilidades ni expectativas, no vivida y mutilada; no está al servicio de la vida sino que es su sustituto patológico. En sociedades como la nuestra, con alto nivel de injusticia, discriminación y bloqueo de canales de ascenso y superación social $y$, a la vez, con fuerte publicidad cotidiana por alcanzar objetos o formas de vida altamente costosas, esta violencia es bastante común entre sus gentes. Es nuestro clásico "vivo", la motivación, por ejemplo, de las "mulas" del narcotráfico. En otras palabras la negativa acepción del ascenso social que no le da espera al trabajo como forma lenta y cotidiana de ahorro y superación, sino que crea necesidades inmediatas que sólo se pueden alcanzar a través de cierto tipo violento de compensación inmediata con daño directo o indirecto hacia otro.

\subsubsection{SED ARCAICA DE SANGRE}

Hace referencia a la pasión de matar como modo de trascender la vida ante el miedo de hacer parte de una historia dinámica, proyectada, que se fija metas y que por lo tanto parte de unos principios sólidos, claros y flexibles. Para los violentos de esta índole-el terrorismo es su más refinada expresión- producir violencia es sentirse fuerte, independiente, único, por encima de todos, realizado, lo que convierte este acto en una obsesión, generalmente de pequeños grupos con ideologías abstrusas y de poco análisis. 
En nuestro medio, este tipo de situaciones se ha vivido en la tanatomía criminal propia de las violencias sociales y en las actuales circunstancias en las que la muerte brutal, lo más brutal y dolorosa posible, es el camino que eligen los grupos violentos, incluidos algunos legales, cuando se van cerrando todas las salidas racionales al conflicto, como reconocimiento a su propia vida como grupo. La usurpación gozosa del derecho a la vida ajena es la mejor forma de satisfacción a la que aspira este tipo de personas o de grupos de personas.

\subsubsection{VIOLENCIA VIRTUAL}

Los medio de comunicación, al utilizar las noticias violentas para atraer al público y vender más, le están haciendo juego al terrorismo; saben que las historias violentas se venden mucho más que aquellas donde predomine la inteligencia, los sentimientos de alegría, solidaridad, la paz, amistad, los valores morales. En consecuencia, vivimos atiborrados de palabras e imágenes violentas, tanto en las noticias como en las películas. Los Estados Unidos hicieron uso de esta violencia para vender una imagen falseada de la guerra del golfo, de la invasión a Afganistán, Irak, de las criminales invasiones a Grenada o a Panamá, entre otras. Si no se ganan las guerras en la realidad o no se puede mostrar la realidad de la guerra, se gana la guerra o se ajusta la versión o se justifica en la virtualidad de las películas.

Es el alimento espiritual en cine, televisión y juegos de vídeo; es la escuela norteamericana que enseña, a través de los Mass-Media, a combatir el crimen con otro crimen, generalmente con un crimen mayor; y que además genera preconceptos: delito o crimen se relaciona con indígenas, negros, latinos, líderes populares y cierta forma de vestir, entre otros.

Pero por otra parte, ha originado en Colombia una curiosa e inmensamente peligrosa figura:
Existen, ante un crimen, dos posibles culpables: el asesino material, quien ejecuta el crimen y el asesino intelectual, quien ordena el crimen; pero al lado de ellos ha surgido otro tipo que es el asesino virtual, aquel que usando los medios masivos de información social, señala a un grupo de personas, a una urbanización, a una vereda, y otros, como presuntos (o sencillamente como acusación directa, sin la posibilidad de la presunción) colaboradores de algún grupo violento colocándolos como objetivo militar en la mira del grupo contrario (es el caso lo que ocurrió con la urbanización Inaía Sué en Bogotá de los señalamientos que hizo tiempo atrás la revista Semana a un grupo de alcaldes como colaboradores de la guerrilla, o los artículos que escribía Panesso Robledo en El Espectador identificando a los sociólogos, a personas en ciertos cargos -Defensoría del pueblo, por ejemplo-, o a quien se le iba ocurriendo sin ningún elemento probatorio como idiotas útiles de la subversión; o lo que hizo permanentemente el gobierno de Uribe (defenderse de la oposición con señalamientos socialmente sensibles: como apátridas o guerrilleros o idiotas útiles de la guerrilla, el caso dramático de Piedad Córdoba es ilustrativo), violando de paso todos los derechos procesales de los supuestos "acusados", pues en Colombia una persona es inocente hasta que un juez no determine lo contrario, $y$ poniendo en la mira de un fusil asesino a comunidades o a personas inermes, por una sospecha, por cierta visión del mundo, o por la presencia de algún elemento circunstancial. Los noticieros, en su afán por la noticia-espectáculo, hacen eco y coadyuvan a recrear la figura del asesino virtual para que otros cometan un crimen real.

\subsubsection{VIOLENCIA PASIVA}

El concepto parece contradictorio porque la violencia es activa por principio. 
Corresponde a actitudes propias de la sociedad civil. La "otredad" como necesidad básica para el crecimiento personal se pierde y aparece como único paradigma la "yoidad" -individualidad cerrada-, que va exterminando los menores rasgos de solidaridad y cooperación cotidiana y ciudadana. Se expresa en los más triviales detalles de la cotidianidad (desde la basura que se arroja por la ventanilla del vehículo hasta la incapacidad de atender a un herido en la calle o de cooperar en las organizaciones de base (juntas de acción comunal, juntas administradoras, y todo tipo de organizaciones cívicas que no dependen del estado sino de la iniciativa ciudadana). La violencia pasiva -0 indiferencia- es causa de muchas formas de injusticia y de discriminación, fomenta la corrupción política por la falta de atención ante el sufragio o ante la participación ciudadana en la dirección y control de lo público, estimula la delincuencia común pues nadie ayuda o defiende a nadie, recrea formas nocivas de existencia como la terminación de la vida comunitaria del barrio a cambio de la aséptica seguridad del conjunto cerrado -lo más cerrado posible- y del centro comercial, genera la incomunicación cotidiana, promueve la comunicación negativa: Yo me "conozco" con mi vecino, con mi compañero de asiento, con "el del lado", para hacer un reclamo por alguna violación -real o supuesta-, de mis derechos individuales a-que-no-se-metan-conmigo.

\subsection{RAÍCES SOCIALES DE LA VIOLENCIA}

La violencia es una manifestación, un producto de situaciones profundas en la vida social, es el fenómeno que aparece con mayor dramatismo en el mundo subdesarrollado, $y$, con toda su fuerza, en el colombiano, como producto de dos enfermedades históricas: la pobreza y la corrupción. La violencia no es una enfermedad, es el dolor producido por la enfermedad.
Pero por otra parte, en el medio colombiano, la manifestación ha llegado a tales extremos que ha terminado por convertirse en parte de la substancia del problema, en un círculo vicioso: el efecto produce una consecuencia, a su vez esta consecuencia se convierte en efecto de algo más álgido, y así pasamos en esta cadena de lo malo, a lo trágico, a lo terrible, luego a lo espantoso, luego a lo demencial, y luego (...), luego al infierno social con extremos que dejan pasmada a la comunidad internacional; pero, a los que estamos adentro del infierno, por una patológica costumbre, ya no nos afecta ni nos inmuta, al contrario, nos sirve de distracción entre reinado y reinado, o entre los dos tiempos de un partido de fútbol. La violencia real del noticiero se ve con el mismo espíritu de la violencia teatral de un realitie o de la violencia ficticia de una telenovela o la serie norteamericana. Es decir, no produce indignación, solo es un distractor en el decadente aburrimiento cotidiano de la vida postmoderna.

\subsubsection{LA POBREZA}

No resulta difícil afirmar que nada permanecerá igual, pero deberíamos agregar que nada puede permanecer igual. La problemática total desplegada ante nosotros, como un abanico que al abrirse revela más y más sorpresas debido a las novedades que encierra, no es sólo una crisis como tal, sino una realidad que exige una reformulación igualmente integral. La "crisis de los fundamentos" que a principios de siglo derribó gran parte de la matemática y mecánica clásicas, se aboca a fines de este siglo a derribar teorías económicas, filosóficas, políticas y sociales en una de las características que distingue al hombre de los demás seres de la naturaleza, su DINÁMICA: capacidad intelectual, capacidad creadora, capacidad de adaptación y sus ilusiones. A través de su historia y de su desarrollo social o encontrando diferentes formas de satisfacer sus necesidades 
fundamentales; pero los últimos tipos de desarrollo aplicados no han tenido otro resultado que cerrarnos las puertas para un futuro, nos han llevado a degenerar la condición humana ya que han generado una serie de conflictos en el interior de los grupos sociales como: violencia, miseria, corrupción, consumismo, analfabetismo, destrucción de los hábitat naturales, la competencia, el individualismo, la pérdida de valor de la persona convertida en "Recurso Humano" -una connotación económica donde lo que importa es su fuerza de trabajo-. (Max-Neef, 1984, p. 44)

Así que la violencia, como ya se dijo, en principio no es el problema, es el efecto del problema. El problema es también la mala distribución de la riqueza o inequidad.

Así, el progreso social no es el crecimiento económico, si no una cuestión humanizada, personalizada; es el armónico desarrollo social, junto con la sostenibilidad de la economía (que no implica una especie de crecimiento $\sin$ fin).

El equilibrio entre desarrollo social, sostenibilidad económico, conservación de la naturaleza y evolución cultural es lo que conduce al progreso integral; es la plenitud del ser humano en el amar, conocer y actuar en armonía con los otros seres humanos y con la naturaleza, es su propia trascendencia al servicio de los demás. Esta integración promueve por sí misma la paz y afirma la armonía social, que no implica ausencia de conflictos, sino superación del conflicto por caminos no violentos.

Es imposible que haya paz donde no hay justicia, socio económica. La justicia socio económica es el camino cierto para fundamentar una nación en construcción de la paz. La paz y la justicia no son regalos, son conquistas inalienables; se logran luchando por eliminar desigualdades, originadas en el abuso, la inequidad y la corrupción pública y privada.

Paz no significa tranquilidad y conformismo o resignación. Pablo VI dijo: "¿Queréis paz?, trabajad por la justicia"; paz significa equilibrio dinámico en el interior de la sociedad. Su requisito es la justicia con el complemento de la libertad, el ser humano nace con vocación para aprender, amar, actuar, para perfeccionarse y evolucionar, prueba de esa evolución es la libertad. Como en un viejo silogismo aristotélico, no existe paz, donde no hay justicia, no existe justicia donde no hay igualdad. La igualdad real es aquella en donde hay igualdad cierta y efectiva de oportunidades.

En la sociedad civil, frente a la justicia y a la libertad, y para no pecar de insulso paternalismo de derechos, existe el deber de la solidaridad. Solidario es quien actúa comprometidamente en una misma causa con otros como si fuera propia. Solidaridad supone conciencia del individuo ante un interés superior al suyo, de tipo comunitario; esa conciencia establece entre las gentes mutua dependencia e interdependencia. Nadie puede pensar en progresar o mejorar, estando completamente solo o en grupos cerrados.

Desde esta perspectiva, en los últimos años, se promueven propuestas con el fin de mejorar las condiciones de vida de la mayoría de los seres humanos, y una de ellas: el desarrollo a escala humana, plantea "un desarrollo que se refiera a personas y no a objetos y cuyo fin no debe ser ni produccionismo ni consumismo, sino la satisfacción de necesidades humanas 
fundamentales que solo son necesidades de poseer sino también necesidades de $\operatorname{ser}^{\prime \prime}$ (p. 245)

Para la solución a problemas de la inequidad y sus consecuencias antes mencionados, se exige la participación de los individuos como actores de su propia historia, estos deben construir poco a poco su futuro, por lo tanto es necesario aprender a optimizar las relaciones interpersonales.

La estrategia que se podría dar sería la de propiciar cambios sustanciales a la sociedad, teniendo en cuenta dos aspectos: la reorganización de la economía y la educación.

En la parte económica sería la formación de pequeños grupos (como los Kibutz en Israel) -en barrios o veredas-, de donde se pasaría de una economía individualista y concentradora de bienes a una ECONOMIA SOCIAL de participación distributiva y armónica entre las personas y los recursos naturales. La economía social se basaría en la autogestión y de beneficio compartido. La empresa estaría formada por grupos de familias asociadas, trabajando en régimen solidario. Necesariamente se debe acoger como partes del modelo y del proceso, las empresas actuales, pero que funcionen bajo criterios de solidaridad. Rompiendo además con nuestro curioso sistema cooperativo actual: cooperativas con dueño a través de la perpetuación de poderosos presidentes de Consejos de Administración que, bajo el disfraz de líderes cooperativos, se perpetúan en el cargo, y terminan manipulando y corrompiendo en beneficio personal y de sus áulicos este noble principio del cooperativismo, en muchas cooperativas además ha habido un fuerte olor a dinero recién lavado.

La clave de todo proceso es la acciónparticipación real de cada persona en la vida política. A la participación económica deben tener acceso todos los integrantes del grupo; a la participación cultural, a través de la capacitación constante y del flujo de información formativa y a la participación social en la medida que satisface sus necesidades fundamentales.

Los cambios que se generen en un grupo social, deben estar fundamentados por el sistema educativo, donde básicamente se deben trabajar dos aspectos:

- Preparar al individuo para que leacritique e interprete su realidad y la transforme de acuerdo a los principios sociales. Es decir, debe ser una educación fundamentada en una metodología de acción-participación.

- Renovación cultural: La formación de empresas comunitarias; es un aspecto económico, pero también cultural y social. Cada empresa comunitaria, será, además de un taller de trabajo, un centro de aprendizaje en su sentido formal e informal. Se aprende en el quehacer. Cada empresa será al mismo tiempo unidad de producción y escuela. De los quehaceres compartidos e integradores se generará una cultura renovada, que producirá personas nuevas, un ser social, de principios firmes, que piense en él mismo con autonomía y en los demás con solidaridad, rompiendo así con el yo heterónomo pequeño-burgués y reemplazando así al hombre egoísta, individualista y ególatra.

La asociación familiar y comunitaria, y todas las características que implica el compromiso, al producir bienes suficientes por el trabajo en equipo, generarán en sus miembros, especialmente en los niños, una conciencia asociativa y solidaria. Todo esto formará seres humanos justos y libres.

Cada empresa comunitaria (pequeños grupos familiares) será una unidad de vida, de trabajo, de educación, un sistema lo más autosuficiente posible. 
En el campo ambiental, los recursos naturales deben determinar la unidad territorial (grupo mayor) -región-; será determinado por las características geográficas, económicas, ecológicas o por combinación de dos de ellas. Se aplicará el concepto de sostenibilidad: el desarrollo humano de la mano del desarrollo de la naturaleza. Qué bueno sería seguir el ejemplo de nuestras culturas precolombinas: "el sistema cultural estaba construido en función de las necesidades impuestas por el manejo del medio" (Maya, 1995), en una nueva ecosofía: ecología social (personal, colectiva, mental, psicológica, etc.), ecología educativa, ecología ambiental y ecología de "el sistema cultural estaba construido en función de las necesidades impuestas por el manejo del medio" a feliz término pues pudieron más las presiones de los gremios productores, importadores y comerciantes del país; de esta forma las mejores tierras y las más productivas siguieron en manos de quienes las tienen como zonas recreativas, de alta producción agroindustrial, que genera grandes utilidades para una sola persona, para grandes hatos ganaderos y hasta para parcelaciones que generan grandes ingresos a sus propietarios. De igual manera, los incentivos para la siembra y la producción de alimentos disminuyeron al dispararse los intereses para los créditos y el precio de los insumos para la misma actividad agrícola y, como si esto fuera poco, el la paz, como una nueva ética estética. (Sánchez, 1995)

Todo plan o proyecto de cambio necesita un dinamizador, pero todos los miembros del grupo social deben aportar su concurso para que los sueños de transformación se den. "Un gran problema requiere de muchas y pequeñas soluciones"; es decir, si queremos transformación del mundo, para mejorar las condiciones de vida de los seres humanos menos favorecidos, debemos empezar por transformar nuestra familia, nuestro barrio o vereda (...) que con el transcurrir del tiempo se podrá generar un nuevo estado que esté al servicio de la sociedad, donde la persona sea parte activa de la vida política y social y a todos nos interese el bien común, no el actual estado lleno de mediocres, mezquinos y corruptos estadistas.

En el campo ya el gobierno ha hecho esfuerzos, todos ellos con magros resultados o con remedios que han resultado peores que la enfermedad; uno de ellos, la tan sonada Reforma Agraria durante el gobierno de Carlos Lleras Restrepo, que desafortunadamente no pudo llevarse gobierno construye una serie de instalaciones y se las adjudican a una gran cantidad de intermediarios y acaparadores, que con el título de comerciantes son los que determinan las políticas reguladoras de precios a sus conveniencias para los productos que demandan trabajo, capital y transporte, ni qué hablar de programas de contra-reforma agraria como AIS y los que impulsó el gobierno del Presidente Uribe.

Parece ser que el mismo gobierno con su permisibilidad y tolerancia, enriquece los bolsillos de todo el gremio de "comerciantes" de productos agrícolas (intermediarios -estafadores con amparo legal-); que son al fin y al cabo los que mantienen su representatividad en una clase política corrupta, que, sin lugar a dudas, es dueña de buena parte de las causas que han llevado a este país a esta guerra fratricida.

Así que, desde las empresas comunitarias rurales, mencionadas anteriormente, se pueden establecer centros de acopio y mercadeo que permitan vencer al voraz intermediario y mejorar la economía campesina. 
Podrían establecerse estos centros de acopio y mercadeo veredales de carácter cooperativo (que ya han funcionado en varias regiones) a través de los pasos siguientes:

- Realizar un estudio orientado a determinar qué productos son los que más se venden e identificar las zonas de más alta productividad de los mismos. Esto permitiría ubicarlos estratégicamente y por ende facilitaría su manejo.

- Reunir a los habitantes productores en las diferentes veredas para instruirlos y a la vez para comprometerlos en el manejo de los mismos centros cooperativos. Así se evitaría lo que en muchas otros proyectos ha sucedido y que ha sido la causa del fracaso, pues muchos comerciantes inescrupulosos, comenzando por los mismos propietarios de los vehículos que sacan la carga al mercado, logran muchas veces a través de engaños y de falsos ofrecimientos, que los miembros de las cooperativas, se vuelvan en contra de su misma institución. Esto sucedió alguna vez en la Cooperativa de Productores de Mora en Sevilla, jurisdicción de Piedecuesta (Santander), en donde los propietarios de camiones que comercializan la carga, lograron desvertebrar la misma cooperativa, para seguirse lucrando ellos mismos con el sudor de otros. Igualmente sucedió en Lebrija (Santander) con los cultivadores de piña. Además de otros casos que son conocidos.

- Solicitar crédito para libre inversión o específicamente para la compra y comercialización de productos, generados por los mismos socios de dichas cooperativas. Actualmente las entidades gubernamentales con sus proyectos como los que se están ofreciendo para la sustitución de cultivos, la diversificación y otros, podrían facilitarlos. Estos mismos créditos podrían ser manejados inclusive a través del aporte de insumos y algún otro recurso.

- Ofrecimiento de crédito para productores que necesiten capital de trabajo, para arriendo de tierras, insumos, y demás. Estos créditos pueden ser manejados incluso a través de la misma cooperativa, de manera que sea la cooperativa quien los administre, pues al fin y al cabo es la entidad que va a comercializar el producto.

- La cooperativa finalmente se encargará de comercializar los productos a muy buenos precios en otros mercados y estudiará igualmente otras alternativas para la producción de derivados de los productos, logrando así una regulación de precios y de salida del mismo producto; esto contribuirá a generar empleo para amas de casa, se beneficiarían igualmente los transportadores de la región, evitando así que se conviertan en armas de doble filo para la misma organización. Estas mismas cooperativas podrán ser oferentes de salud, educación y recreación, para asegurar así un mejor desarrollo sostenible.

De esta manera si "el campo productivo se ha convertido hoy en día en campo de batalla", otra vez puede regresar Co"El campo lombia al camino productivo se ha de la utopía indígeconvertido hoy na, desvertebrada por los invasores en día en campo europeos y por la de batalla" economía exacerbadamente individualista y competitiva, al sueño del campo productivo para quien produce, para quien trabaja. El bienestar campesino y la equitativa repartición de tierras es el fundamento del progreso armónico y de la paz en el campo. Los menos culpables de su situación y de la violencia rural son los mismos campesinos, bien lo dicen en su folclor popular: 
Yo soy campesino puro

y no empecé la pelea,

pero si me buscan ruido

la bailan con la más fea

Así cantaban en los tiempos de la violencia política, pero así sigue siendo la realidad que hace violento el campo por factores exógenos que terminan por descomponer la sociedad, la cultura y la economía campesina (los grupos violentos, el desempleo, el monopolio de tierras, aperturas salvajes e irresponsables que han impactado la médula de la vida campesina como la propiciada en el gobierno de Gaviria Trujillo, el narcotráfico, la corrupción política, entre otros).

Una profunda y radical reforma agraria, que devuelva la tierra a los campesinos y produzca mediante sistemas de economía solidaria, sigue siendo una deuda sin pagar en Colombia y es uno de los fenómenos que influye de modo determinante en la ruptura histórica entre el estado y la sociedad.

\subsubsection{LA CORRUPCIÓN}

Son muchas las causas de la ausencia de paz en Colombia, pero, así como se propone como derecho síntesis a la paz, (Uribe Vargas, 1996) podría imaginarse una causa síntesis de las raíces sociales del problema en dos conceptos: pobreza y corrupción.

En esta parte se va a hacer referencia a la corrupción sin desconocer que la pobreza, a la que se hizo referencia en el numeral anterior, es, en muchas ocasiones, causa de la corrupción, pero no la única, porque si bien la pobreza puede conducir a la corrupción y a la violencia, así mismo la ambición es otra causa, cada vez más generalizada y más dañina, de la corrupción.

La corrupción también tiene muchas manifestaciones no todas ilegales, por ejemplo, la seca avaricia de los ricos -que los conduce a pagar el inmoral

"la tendencia salario mínimo o común a a obtener ganancias exorbitantes-, quedarse con lo la tendencia común ajeno, a afirmar a quedarse con lo que "lo que se ajeno, a afirmar que "lo que se encuenencuentra no tra no tiene dueño", tiene dueño" la mediocridad e indolencia de los maestros frente a su educandos, los intereses y el cobro de servicios bancarios en fin, la lista saldría bastante larga.

La corrupción de los empleados públicos, es otra de las formas que incide de manera muy notoria y delicada en el agravamiento de la violencia nacional y en la violación de los Derechos Humanos porque genera pobreza social y resentimiento frente al estado.

Así que, la causa única de la corrupción no es la pobreza, porque los que hacen más daño en las cadenas de la corrupción son los que tienen más (políticos, grandes comerciantes, industriales, etc.) con sobornos, prevaricatos, evasión de impuestos, contrabando, baja calidad de bienes y servicios, precios exorbitantes, salarios inmorales (como el inmoral salario mínimo), evasión de la seguridad social, contratos laborales leoninos, cooperativa de trabajos asociados para tercerizar el trabajo y suprimir derechos de los trabajos, entre otros.

Lo anterior implica que, sin desconocer que la pobreza es una fuente de corrupción, generalmente no por inmoralidad del que roba, o sea, deseo expreso de hacer daño, sino urgido por diversas necesidades, ya vitales o desafortunadamente -y producto de la manipulacióncreadas artificialmente por la publicidad; es también, y en la misma magnitud, un problema cultural, de ambición personal y reconocimiento social positivo (el des- 
honesto hoy en día no es un vulgar ladrón sino un "vivo" que se admira y adula; el contrabandista, el extorsionador de casa de empeño, el empresario que paga salarios mínimos, el político corrupto, entre otros, son personas de éxito dignas de imitar, el narcotraficante, el "traqueto" son verdaderos paradigmas sociales).

Así la corrupción por ambición, es, por puro sentido común, inmensamente más inmoral, y dentro de esta modalidad, la corrupción pública es mucho más dañina, la más dañina de todas, por lo que debe ser combatida y penada con mucha más fuerza. Debe ser mucho más severa, por ejemplo, la pena para el con-

“los trapos sucios se lavan en casa" $y$ "el vivo vive del bobo y el bobo de papá y mamá" y "si le dan papaya aproveche" y "lo que se encuentra no tiene dueño"... ayuda y saca provecho de dichos populares según los cuales "los trapos sucios se lavan en casa" y "el vivo vive del bobo y el bobo de papá y mamá" y "si le dan papaya aproveche" $\mathrm{y}$ "lo que se encuentra no tiene dueño"..., en fin, la inmoralidad difusa del "vivo", con lo que llegamos a una doble moral compartida, en la que se critica en otros aquello que yo también estoy dispuesto a hacer si tuviera la oportunidad.

La corrupción se multiplica cuando la vida pública hace lugar a lo que los italianos llaman el "perdonismo", cuando la clase política practica el amiguismo y los ocupantes de roles de poder el nepotismo, cuando los dirigentes emplean la auto absolución como hábito aceptado y cunde la sensación de que nadie pedirá cuentas. Los confines entre lo lícito y lo ilícito pierden nitidez. También, obviamente, la frontera entre lo bueno y lo malo.

Igualmente cuando socialmente se considera necesario cierto nivel supuestamente aceptable de corrupción, en el lenguaje popular: "el problema no es lo que robe, sino que se la robe toda" o "que no deje nada para invertir", "robó pero se vieron las obras", "cada uno tiene derecho a 'sacar' lo suyo", "le dimos su comisión al doctor por la obrita, tenemos que ser agradecidos y entender...", "todos tenemos derecho a comer (...)". Así los mismos ciudadanos legitiman la corrupción casi como un incentivo necesario para que los políticos actúen a favor de una región o estimulen tal o cual obra.

La corrupción, en fin, es en sí misma un antivalor, pero si se propone y practica la política como un antivalor, la corrupción termina siendo un pragmatismo político "necesario", criticado en público pero aceptado en privado por los gobernantes y por la misma gente. Habría qué ver si la 
gente critica a los corruptos por sólidos principios éticos del que critica o por simple y pura envidia. Si se propone la política como un valor, el nexo entre ética y política es claro e ineludible. La impugnación secular a la corrupción intoxicante -que habita en todos los países pero crece con más facilidad en el subdesarrollo político, económico y moral- se ha traducido, con éxito razonable, en ocasiones prolongadas de respeto a la política como pedagogía y servicio, de ejemplaridad como atributo dirigente, de justicia independiente y veloz como garantía contra la impunidad, de instituciones deliberativas como control, de una prensa y unos medios de comunicación como ámbitos de denuncia y de crítica; la modestia de los hombres públicos en lugar de la megalomanía.

En las sociedades que fun- "el problema no es lo que robe, sino que se la robe toda" "que no deje nada para invertir", "robó pero se vieron las obras", "cada uno tiene derecho a 'sacar'lo suyo", “le dimos su comisión al doctor por la obrita, tenemos que ser agradecidos y entender...", "todos tenemos derecho a comer..." cionan, el denunciado por corrupción se preocupa, no sólo por demostrar su inocencia o por entorpecer la justicia con argucias legales para que no se demuestre su culpabilidad, si no que se alarma también cuando la gente cree verosímil la denuncia; es el referente éticopúblico, que en nuestro medio no tiene importancia si el cuestionado ha hecho el dinero suficiente para "tapar" la falta con plata, al final termina convertido en un paradigma social por ser un "vivo" digno de admiración y de imitación o por su posibilidad de mover influencias, no importa cómo ni de qué manera lo haga. Por eso el delito de los hombres públicos es mucho más grave y debe sufrir una condena más severa en las más duras cárceles, porque al delito mismo se le suma el daño moral que hace a toda la sociedad.

En el caso concreto de Colombia, el fenómeno de la corrupción política au- menta con el grado de ineficiencia en el cual se desarrolla la actividad de las instituciones, con la discrecionalidad de los funcionarios, con el grado de monopolio sobre los servicios que prestan, con los ingresos que pueden obtenerse en las actividades corruptas, con la nula sanción social sobre los individuos corruptos, con una baja probabilidad de ser descubiertos, con unos mínimos castigos para los corruptos y con cárceles de lujo para los más dañinos.

La ineficiencia es una de las causas más importantes de la corrupción. La ineficiencia reduce la calidad del servicio que las entidades prestan al público $\mathrm{y}$, por consiguiente, crea estímulos tanto para que el cliente ofrezca dinero a cambio de la obtención del servicio como para que el funcionario se involucre en este tipo de transacciones.

Dentro de la administración del Estado no hay un sistema que premie la gestión eficiente y castigue la ineficiencia. Un sistema de carrera administrativa que tiene fuerza legal, pero que no está basado en la promoción o sanción de acuerdo con el mérito, tiende a generar estabilidad laboral para el personal ineficiente o corrupto, y escasas motivaciones para los buenos profesionales.

Otra de las causas es la mala calidad del control, en donde la corrupción aumenta cuanto menores sean, tanto la probabilidad de que el agente corrupto sea descubierto, como la fuerza del castigo (cuando se aplica).

Los mecanismos de control de los resultados de la gestión pública en Colombia son de baja calidad, tanto en lo que se refiere al control puramente ad- 
ministrativo e interno de las instituciones como al castigo penal a cargo de agentes externos (por ejemplo, el sistema judicial).

Aparte de esta falla esencial, los procedimientos de control que existen no se cumplen. En la teoría y en la letra de las leyes, la responsabilidad de los funcionarios puede manifestarse en cuatro tipos de consecuencias: civiles, disciplinarias, penales y políticas.

La responsabilidad civil puede llegar a afectar el patrimonio de los empleados públicos por los daños que por su culpa grave o dolo se ocasionen sobre el patrimonio público y también sobre el de los particulares. En la práctica estas consecuencias no llegan a producirse, pues por lo general los particulares lesionados realizan acciones contra las entidades y no toman acciones directas contra el funcionario.

La responsabilidad política existe, teóricamente, para los altos funcionarios y requiere, para que se haga efectiva, la acción del Congreso; pero éste último a su vez es el que alienta y mantiene desde sus recintos estos altos funcionarios y a su propia corrupción, la más acendrada y putrefacta de todas.

Algo de responsabilidad penal ha resultado últimamente; producto de tres cosas: de la Fiscalía, en la que ha habido algunos resultados en medio de azarosos manejos, de la honesta y proba labor de algunos funcionarios medios de la contraloría y la procuraduría; y del trabajo de las altas cortes, empeñadas, casi en solitario, en hacer justicia sin que el tráfico de influencias medie en su aplicación; tal vez habría una cuarta y maquiavélica causa: la misma clase política necesita de vez en cuando quemar a algunos de sus miembros para mantenerse, en un viejo proceso de reciclaje político.

Así mismo, los funcionarios le dan la mayor prioridad al cumplimiento de los requisitos ordenados por las normas que al cumplimiento de su verdadera responsabilidad, es decir, al logro de unos objetivos de gestión. La tramitomanía y un ambiente institucional caracterizado por la falta de compromiso con el cumplimiento de objetivos de gestión constituyen un entorno ideal para el surgimiento de la corrupción.

En fin, luchar contra la corrupción pública no es nada sencillo; pues la tenencia de dinero genera aprecio social, y su carencia lleva a la situación contraria; lo que hace que el atractivo del dinero sea lo suficientemente grande como para que se olviden los reparos respecto de la forma como éste es obtenido; desde el punto de vista de la actividad social de una persona, en Colombia probablemente causa una sanción social mayor no obtener dinero que haberlo obtenido a través de la corrupción.

Esto hace parte de un ambiente general en el cual el tráfico de influencias es mirado con benevolencia y el uso de recursos públicos para fines privados es considerado como una prerrogativa normal asociada al logro de altas posiciones de mando en el sector público.

La ciudadanía no ha encontrado vínculos efectivos para presionar por una solución efectiva y real de la corrupción, en buena parte debido a que su posición respecto del tema es ambigua, pues los actos corruptos existen precisamente porque hay agentes privados dispuestos a involucrarse en ellos.

Quienes en el sector privado se rasgan las vestiduras por los casos de corrupción muchas veces pasan por alto que detrás de todo funcionario corrupto generalmente existe un ciudadano o una empresa que propicia en privado la corrupción que públicamente condena.

Como uno de los intentos en la lucha anticorrupción nació la organización 
Transparencia Internacional que vino a instalar su capítulo en el país como alternativa para erradicar las prácticas corruptas de las diferentes esferas políticas, económicas y sociales de Colombia.

A través del capítulo colombiano, el país podrá participar activamente en la elaboración de estrategias que permitan detectar y prevenir las fisuras que desangran el erario y el patrimonio de entidades privadas. Transparencia Colombia hace parte, como capítulo nacional, de Transparencia Internacional, creada en 1987. Es la organización más grande y prestigiosa del mundo en la lucha contra la corrupción. Desde su fundación ha logrado importantes resultados en países como Alemania, Italia y Estados Unidos. Sus oficinas centrales se encuentran en Berlín. Tiene cerca de cien capítulos nacionales en todos los continentes.

Hace algún tiempo, por los medios de información masiva, el Presidente Gaviria condenó públicamente las actividades de esta entidad, mientras crecían los escándalos en Caprecom, Adpostal, Alcaldía de Bucaramanga, más miembros de la clase política iban a la cárcel, etc., etc. Sobran los comentarios. En los ocho años del gobierno de Uribe hubo tantos escándalos que se perdía la capacidad de seguimiento e incluso de asombro y ni hablar de todos los escándalos que empiezan a destaparse de manera vertiginosa el comienzo del gobierno del Presidente Santos. $^{9}$

Aquí queda una deuda pendiente: el análisis de cierto modo de "corrupción legalizada" mediante costos inmorales en ciertos servicios: los altos costos bancarios, el precio de la gasolina, las invasiones legales en terrenos no aptos para la construcción, ${ }^{10}$ los sobrecostos en las obras públicas, las interminables intermediaciones que encarecen las obras del Estado (...) en fin(...) la cosa es de tal tamaño que sobrepasa la imaginación del más avezado escritor de realismo mágico.

\section{A MANERA DE CONCLUSIÓN:}

\section{IMAGINÉMONOS LA PAZ... CON JUSTICIA Y LIBERTAD}

\author{
"Lo más malo de la gente mala \\ es el silencio de la gente buena". \\ Bertold Brecht
}

En el ahondamiento de la dicotomía entre el estado y la sociedad civil, la corrupción y la pobreza y su hija la violencia crecen de manera inusitada y generan un escenario en el que las acciones comunicativas se fundan en lo pragmático, en el acto utilitario que percibe al otro como una oportunidad y no como un sujeto de derechos, y se va construyendo un modo social de ser fundado en lo patológico y, en consecuencia, los individuos formados en ese medio no alcanzan a concebir la patología sino que ven las acciones de corrupción, ambición y violencia, sino como buenas, sí por lo menos como necesarias y propias de la vida, como si fuera "natural" ser corrupto o violento. Así la paz, “Lo más malo de la gente mala es el silencio de la gente buena". Bertold Brecht de derechos se convierte en la principal víctima de este proceso.

Entonces, imaginar la paz (entendida como el Derecho de Derechos o la realización de todos los derechos) en nuestro violento país -que si es catalogado como "violento" en un mundo lleno de violencia es porque el asunto ha llegado bien abajo-, es un ejercicio harto difícil; con el peligro de hacer el ridículo, de andar proponiendo sandeces, imposibles o cuentos de novela rosa, en otras palabras, con el peligro de terminar en discurso de campaña política.

De esta manera, la paz, expresada como un DERECHO SÍNTESIS de los otros derechos humanos, (Uribe Vargas, 1996) 
con fundamento en la dignidad humana y de manera integral: la paz como la mayor ausencia de violencia contra todos los derechos humanos, como la actitud dialógica frente a la resolución de todo tipo de conflictos y como propósito universal a la vez que con las garantías jurídicopolíticas necesarias para su protección real y efectiva, sin este sentido de la paz todo el resto de las prerrogativas individuales y sociales carecen de posibilidad real de realización. Esta es la garantía indispensable y a la vez la realización de los derechos fundamentales, pues sin PAZ no es posible la dignidad humana, pero, a su vez, el reconocimiento y la garantía real de la dignidad humana son el fundamento de la paz. El derecho a la vida, a la integridad personal, la realización de los derechos económicos, sociales, culturales y económicos, al conjunto de libertades -de conciencia, de culto, de palabra, de reunión, de asociación-, quedan supeditados en la práctica a que la paz sea una realidad, pero a su vez son la única garantía para la construcción de la paz; en un giro dialéctico en permanente construcción histórica.

La paz implica el deber de todo individuo a contribuir con sus esfuerzos en su construcción y mantenimiento, en la recuperación del sentido de ciudadano como constructor del estado, a ser defensor de lo público, a desarrollar el sentido de solidaridad con "el otro como tercero" (P. Ricoeur), ${ }^{11}$ en el rechazo a cohonestar con las distintas formas de violencia (económica, política, intrafamiliar, armada, y las demás.) y en el derecho colectivo de todo Estado a beneficiarse del pleno respeto por parte de otros Estados.
Desde el punto de vista del individuo, "mientras exista un hombre al que la guerra pueda traer ventajas, y este hombre tenga poder e influencias suficientes como para desencadenarla, toda lucha contra esa conflagración será infructuosa" (Schnitzler); así que para humanizar los conflictos (la guerra entre otros), primero hay que humanizar al individuo.

En este nivel de las relaciones intersubjetivas, Diego Uribe Vargas -con mucho acierto- propone a la paz como derecho síntesis y estimula a la reflexión serena "aprendiendo a escucharnos recíprocamente, abandonando los esquemas de verdades absolutas y tratando de encontrar una verdad síntesis...". Considera la cultura y la pedagogía de la paz como instrumentos para conseguir la humanización de la guerra mediante el derecho internacional humanitario y las perspectivas y conveniencias de la veeduría y mediación internacional en el conflicto armado; pero, además del conflicto armado, hay otras formas de violencia, como ya se mencionó, que enmarcan y alimentan esta guerra; así que, repitamos lo sabido, el silencio de algunos fusiles no es la paz.
"La paz no es sólo
el silencio de las armas, sino el esfuerzo conjunto para construir una sociedad más justa"
Lo individual-cotidiano es uno de los principios fundamentales de la paz y una de las más claras manifestaciones de bienestar social, pues, lo dice el mismo Uribe Vargas, "La paz no es sólo el silencio de las armas, sino el esfuerzo conjunto para construir una sociedad más justa". En este sentido, el derecho a la paz es un derecho individual y colectivo, pero, a la vez, está explícitamente normado como un deber y como una obligación de las personas para procurarlo y exigirlo. 
Ahora bien lo cotidiano, a su vez, también es un reflejo de la institucionalidad (política, económica, social y cultural); por esta razón, la ausencia de relaciones cotidianas intersubjetivas pacíficas y dialógicas o el fracaso en el silenciamiento de las armas, tiene una razón de fondo: la ambición de los apátridas dueños de la economía nacional y la corrupción de los indolentes administradores de lo público o ambas cosas a la vez; pues, como se dijo anteriormente, la corrupción y la ambición son las causas síntesis de la ausencia o violación de todos los derechos, es el origen de la gran mayoría de nuestros males y es la base de toda violencia.

Reafirmando, el derecho a la paz, entendido como ausencia de toda violencia (política, cultural, económica, intrafamiliar, religiosa, sexista, armada, u otra) contra los Derechos Humanos (recalquemos: contra todos los Derechos Humanos), se constituye, de esta manera en el derecho síntesis o en la realización de todos los derechos a partir del Derecho básico: El Derecho a la Vida. La violación de cualquiera de los Derechos Humanos, supone una violación del Derecho a una Vida Digna o una barrera en la realización de la síntesis de todos los derechos: el derecho a la paz.

De esta manera, mientras en Colombia la clase propietaria de la economía y la administradora de lo político, sigan creyendo en lo que saben que no es cierto: que la paz es esencialmente el silencio de las armas, y no contribuyan a la terminación de la violencia económica y de la violencia política del Estado (que producen muchos más muertos -por hambre, abandono, marginalidad, y demás causas- que la violencia armada), la dicotomía entre el Estado como ente jurídico-político de legalidad y de legitimidad formal y la sociedad como mundo de vida, de la realidad, seguirá ahondándose y agravando todas las formas de violencia que asesinan, entre la miseria, la ambición, la corrupción y la exclusión, el futuro del pueblo colombiano.

\section{Notas}

${ }^{1}$ El nuevo enfoque de los derechos humanos es una concepción de la vida social que procura reconciliar la moral, la política y el derecho en un horizonte ético pero al mismo tiempo operacional, que ha avanzado en una visión de política pública. Estos tres órdenes habían sido separados por las concepciones positivistas, las cuales pusieron énfasis en los aspectos lógicos y procedimentales de la ley, perdiendo la perspectiva de las vinculaciones políticas y morales que tiene ésta. La consecuencia que tiene este proceso de incorporación de los derechos de los grupos sociales que han estado excluidos en el derecho positivo actual, ha provocado un redimensionamiento del derecho como tal. Pero al mismo tiempo, ha replanteado las formas tradicionales de hacer política de parte de los movimientos sociales, ya que éstos se han visto obligados a actuar dentro de la institucionalidad formal y a desarrollar estrategias viables de reconfiguración del proceso de integración social. También han sometido a un cuestionamiento profundo a las instituciones sociales $y$ públicas. (Guendel). Incluso en lo político, los ciudadanos acuden con mayor frecuencia a los tribunales de justicia para obtener aquellos resultados que ya no esperan conseguir por medio de las urnas (así ejerzan su derecho al voto). El juez va tomando importancia inusitada en la esfera política. La sentencia termina por 
considerarse una forma superior de participación y materialización de derechos que la votación o que los mismos órganos de representación popular. Esto en cuanto a la aptitud para producir resultados concretos y tangibles. Es el caso patético de la tutela en Colombia.

2 Entre otras fuentes: http://www. elespectador.com/noticias/elmundo/ articulo-316144-fao-denuncia-problemasde-corrupcion-acceso-tierra-61-paises. Diciembre de 2011

${ }^{3}$ Basta con mirar el informe de desarrollo humano. De acuerdo con el índice de Gini, Colombia ocupa los primeros deshonrosos lugares como uno de los países con mayor brecha entre ricos y pobres en el mundo.

${ }^{4}$ Convivir en su acepción colombiana, se ha convertido en un decir amargamente irónico-gracias a los que, con ínfulas de héroes decimonónicos, pretenden apagar el fuego con gasolina-; más bien malvivir en medio de la violencia, la intolerancia, la ambición y la corrupción de todos; pero especialmente de la dirigencia bipartidista tradicional (la mayor culpable en este conflicto), de los propietarios de la economía; inclusive de sectores de la Iglesia Católica, de los movimientos radicales de izquierda y derecha que andan por los peligrosos y fétidos pantanos del fanatismo y del terrorismo, y de algunos movimientos sociales y sindicales que se han vendido al mejor postor o se han politizado perversamente para utilizar su mezquino poder en su beneficio personal o de grupo; unos por acción y otros por omisión.

${ }^{5}$ Inclusive "votar" termina por ser sólo una "sensación" de participación, pero finalmente se relegan en el gobernante, sin mayor control social, todas las responsabilidades históricas.

6 "Debe entenderse una asociación de dominación cuando y en la medida en que aplica para la garantía de su orden la coacción psíquica, concediendo y rehusando bienes de salvación (coacción hierocrática)". (Weber, 1977)

7 Por ejemplo, se dice con frecuencia que las FARC eligieron a Pastrana y luego influyeron de modo contrario para elegir a Uribe. Además es muy común el voto utilitario: por el regalo inmediato, por la obra prometida al barrio o a la vereda, por el puesto para el hijo, o los votos reactivos y emocionales; pero, de ningún modo, o casi por excepción, con la suficiente madurez política o proyección ciudadana como construcción de país, ni siquiera de región.

${ }^{8}$ En esta parte, algunas reflexiones han sido fundamentadas en: (Acebedo Afanador \& Parra Ramírez, Apuntes para la paz: perspectivas pedagógicas, 1999

9 En los municipios es dramático: "Índice municipal: En la medición piloto del Índice de Transparencia Municipal participaron 252 municipios. El 53.4\% de los municipios participantes registró niveles bajo y muy bajo de transparencia, mientras que el $46.58 \%$ alcanzó un nivel medio y ninguno de los municipios participantes en este ejercicio piloto se ubicó en el nivel alto de transparencia. Este año el ITM está evaluando alrededor de 250 municipios". (Transparencia_Colombia). $Y$ téngase en cuenta que el estado en su nivel municipal representa una mayor cercanía para el ciudadano.

Igual ocurre en el ámbito nacional. De la misma fuente (Entidades nacionales): “El Índice de Transparencia Departamental en su última medición (2004-2005) mostró cómo un $48 \%$ de las entidades evaluadas estaban en alto y muy alto riesgo de corrupción. El promedio general de las entidades se mantuvo en 51/100, tan sólo dos puntos por encima de la anterior medición que fue de 49/100. Sin embargo, se registraron avances en la disposición de las entidades a ser eva- 
luadas, 153 de 268 entidades subieron puntos en su calificación." (Transparencia_Colombia).

${ }^{10}$ Generalmente en la prensa aparece el pequeño escándalo de la invasión de los pobres y la reacción de la policía, eso hace noticia para un público ávido de morbo-espectáculo, "da rating". Pero la gran invasión legalizada, la que empieza a aparecer con las inundaciones en Bogotá o en los cerros de la misma ciudad y en muchas otras ciudades, por tener apariencia legal o por requerir de investigaciones sesudas, profundas e incluso riesgosas, no genera ningún tipo de control ciudadano ni del estado mismo ni tampoco de denuncia periodística (a no ser de modo marginal), hasta que viene la tragedia y es demasiado tarde y los culpables terminan por difuminarse sin mayor claridad entre el estado, los interventores y los constructores. $Y$ el periodismo vuelve y juega a lo más fácil: al morbo-espectáculo, repiten hasta la saciedad la filmación "oportuna" del deslizamiento de la tierra o la crecida del río, en fin, la morbo-tragedia-espectáculo y luego hacen altruismo: recogen mercados para los damnificados; pero las investigaciones profundas, el seguimiento, las denuncias, usualmente quedan a medias o definitivamente se olvidan apenas la situación trágica ya no genera espectáculo para el público, además está de por medio el peso del poder de los contratos de publicidad.

11 "El otro" se aparece ante mí de dos formas: el otro como rostro (que conozco, que amo, que me significa y por el que lucho en mi fuero privado e individual) y el otro como tercero (que no conozco, que no amo, que no pertenece a mi ámbito privado, que incluso es diferente de muchas maneras, pero que está ahí, más próximo o lejano, conformando sociedad, construyendo conmigo la misma red social a la que pertenezco y me sostiene). Es en el otro como tercero (por el cual el individuo sale de su puro fuero privado y construye tejido social con otros que no conoce) en el que se encuentra uno de los sentidos estructurales del ejercicio de construcción de ciudadanía. (Levinas, 2000) "Además de esta práctica del compromiso, la formación del vínculo político que nos hace ciudadanos de una comunidad histórica quizás no procede únicamente de la preocupación por la seguridad y la defensa de los intereses particulares de esta comunidad, sino también de algo parecido a una 'amistad política', esencialmente pacífica”. (Ricoeur)

\section{Referencias}

ACEBEDO AFANADOR, M. J. (1995). Ser o comprar: entre la virtud y la competencia. Revista TEMAS Vol. $2\left(\mathrm{~N}^{\circ} 2\right)$

ACEBEDO AFANADOR, M. J., \& Parra Ramírez, M. (1999). Apuntes para la paz: perspectivas pedagógicas. Especialización en Educación en Derechos Humanos . Bucaramanga: Universidad Santo Tomás.

ARENDT, H. (2003). La Condición Humana. Buenos Aires

BOBBIO, N. (1987). Estado, Gobierno y Sociedad. Barcelona: Plaza y Janés.

FROMM, E. (1982). El corazón del hombre. Méjico: Colección Popular.

FROMM, E. (2008). El miedo a la liberdad. Barcelona: Paidós Ibérica.

GUENDEL, L. (s.f.). Políticas Públicas y Derechos Humanos. Recuperado el 15 de Octubre de 2011 de Instituto Internacional de Gobernabilidad: www.amnistiacatalunya.org/edu/2/dh/dh-der-yder-guendel.html.

HABERMAS, J. (1999). Teoría de la acción comunicativa (Vol. 2). Madrid: Taurus.

LEVINAS, E. (2000). Ética e infinito. Madrid. Madrid: Machado Libros.

MAX-NEEF, M. (1984). Economía descalza. Bogotá: Fundación Fica - Fundación soñemos la tierra.

MAYA, A. A. (1995). Perspectiva Pedagógica en Educación Ambiental Desarrollo y Medio Ambiente. Bogotá: Tercer Mundo Editores.

MOLANO BRAVO, A. (11 de Abril de 1996). El Estado en crisis. El Espectador

POULANTZAS, N. (1977). Poder Político y Clases Sociales en el Estado Capitalista. Méjico: Siglo XXI Editores.

RAMÍREZ V., J. E. (1996). Sombras sobre la crisis. Revista Colombia Hoy (N $\left.{ }^{\circ} 144\right)$

REVISTA SEMANA. (MARZO 5 DE 1996). REVISTA SEMANA

RICOEUR, P. (s.f.). Volverse capaz de ser reconocido. Recuperado el 12 de Diciembre de 2011, de France Diplomatiqué: http://www.diplomatie.gouv.fr/fr/ IMG/pdf/Revue_des_revues_200_112B78.pdf

SAN AGUSTÍN. (1999). CONFESIONES. BUENOS AIRES: LUMEN.

SÁNCHEZ, R. (1995). Poder y medio Ambiente. Bogotá: Instituto para el desarrollo de la Democracia Luis Carlos Galán Sarmiento.

SCHNITZLER, A. De la Guerra y la paz. Buenos Aires: Emecé editores. Cuadernos de grandes ensayistas. Citado en: Uribe Vargas, D. (1996). EI Derecho a la Paz. Bogotá: Universidad Nacional de Colombia.

TRANSPARENCIA COLOMBIA. (S.F.). TRANSPARENCIA 
COLOMBIA. RECUPERADO EL 12 DE NOVIEMBRE

DE 2011, de http://www.transparenciacolombia. org.co/LACORRUPCION/tabid/62/language/es-ES/

Default.aspx: http://www.transparenciacolombia. org.co/LACORRUPCION/tabid/62/language/es-ES/ Default.aspx

URIBE VARGAS, D. (1996). El Derecho a la Paz. Bogotá: Universidad Nacional de Colombia.

VARGAS VELÁSOUEZ, A. (Septiembre de 1992). La democracia en Colombia: ¿Al final del túnel o en la mitad del laberinto? Memorias del simposio: Identidad democrática y poderes populare , 25. Bogotá D.C.

VARGAS VELÁSOUEZ, A. Participación y Democracia en Colombia. En Varios, Democracia Formal y Real (pág. P. 72). Bogotá D.C.: Instituto para el desarrollo de la Democracia "Luis Carlos Galán Sarmiento".

WEBER, M. (1977). Economía y Sociedad (Vol. V. 2). Bogotá D.C.: Fondo de Cultura Económica. 